\title{
Experimental evaluation and theoretical modeling of oxygen transfer rate for the newly developed hollow fiber bioreactor with three compartments
}

\author{
Ali Hilal-Alnaqbi ${ }^{\mathrm{a}, *}$, Abdel-Hamid I. Mourad ${ }^{\mathrm{a}}$, Basem F. Yousef ${ }^{\mathrm{a}}$ and John D.S. Gaylor ${ }^{\mathrm{b}}$ \\ ${ }^{a}$ Mechanical Engineering Department, United Arab Emirates University, Al Ain, UAE \\ ${ }^{\mathrm{b}}$ Bioengineering Unit, Wolfson Centre, University of Strathclyde, Glasgow, UK
}

Received 10 July 2012

Accepted 14 May 2013

\begin{abstract}
Bioartificial liver support provides a bridge to transplantation which is at present the only proven specific treatment for acute liver failure. In this paper, a novel multi-coaxial hollow fiber bioreactor so-called "Fibre-in-Fibre FIF Bioartificial liver device" with three compartments is experimentally and mathematically studied. The mathematical model in this paper is an extension of Krogh cylinder model for hollow fibre devices by including one more zone for oxygen transfer, i.e. oxygenation compartment. Three simultaneous linear differential equations were derived for pressure in plasma and cell compartments and flow rate in cell compartment. To validate the model, Oxygen Transfer Rate and hydrostatic pressure experimental measurements for different flow rates, $17-400 \mathrm{ml} / \mathrm{min}$, and different number of hollow fibres pairs are used. Several important parameters of the Michaelis-Menten was investigated, namely, constant $V_{\max }$ (the maximum oxygen consumption per unit volume of the cell mass), the oxygen partial pressure, the flow rate of the perfusate at device inlet. The results showed that the oxygenation compartment should easily secure Oxygen to the cells in compartment B.
\end{abstract}

Keywords: Hepatocytes, artificial liver, bioartificial liver, fibre-in-fibre bioreactor, FIF bioreactor, bioreactor

\section{Notations}

BAL bio artificial liver

Comp. A compartment $\mathrm{A}\left(0.0 \leqslant r \leqslant R_{1}\right)$

Comp. B compartment $\mathrm{B}\left(R_{2} \leqslant r \leqslant R_{3}\right)$

Comp. C compartment $\mathrm{C}\left(R_{4}<r\right)$ (the spaces between the inner diameter of the outer shell and outer hollow fibres, this represents the active area)

$D_{m} \quad$ diffusion coefficient of oxygen in outer fibre membrane

IA compartment A inlet

HF hollow fiber

\footnotetext{
*Address for correspondence: Ali Hilal-Alnaqbi, MSc MBA PhD Post-Doc (Harvard), Assistant Professor, COE, Department of Mechanical Engineering, BioEngineering, UAE University, P.O. Box 17555, Al Ain, UAE. Tel.: +971 50 6725333; +917 3 7133055; E-mail: alihilal@uaeu.ac.ae.
} 


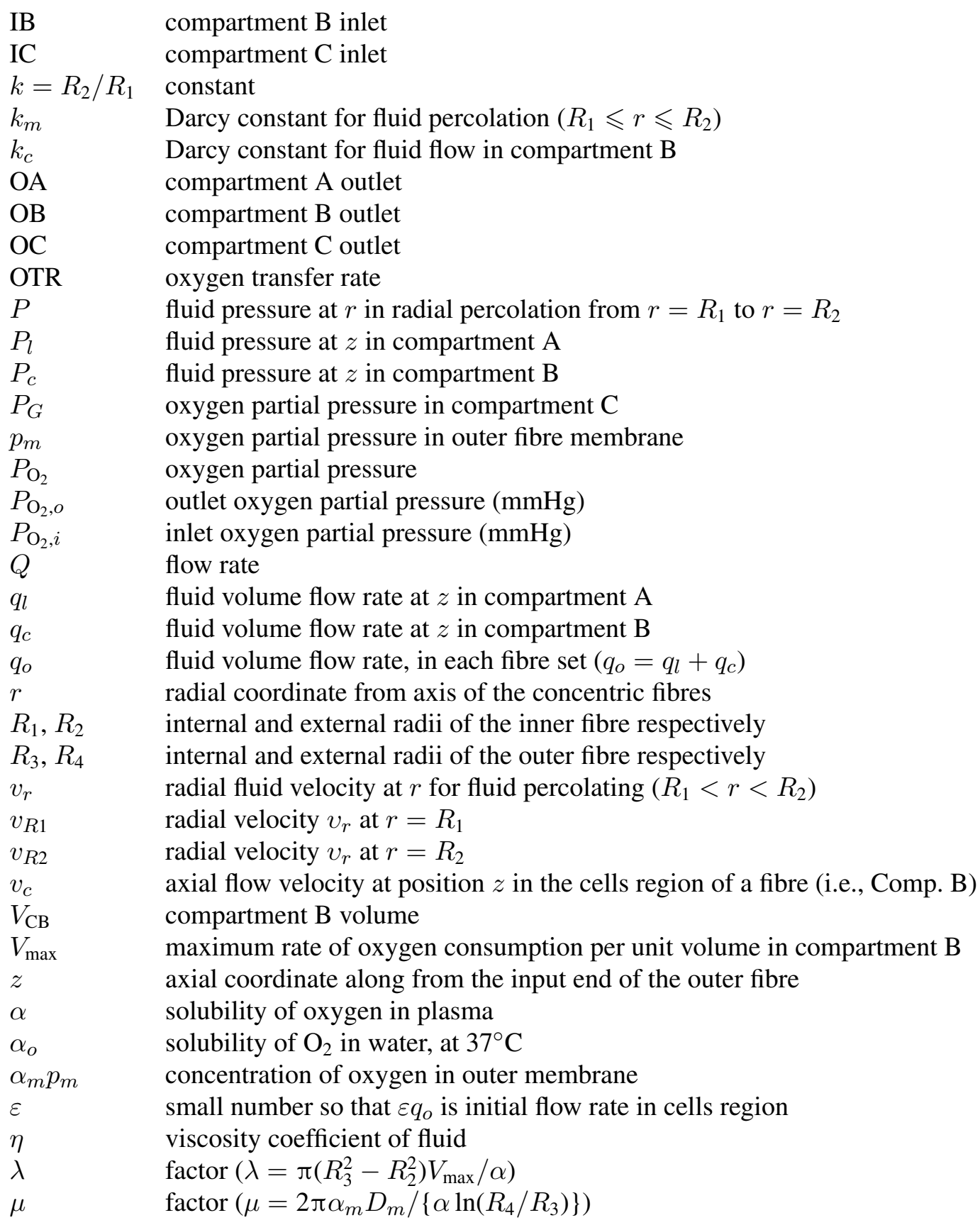

\section{Introduction}

Numerous groups worldwide are currently developing and evaluating BAL devices. Some designs have already reached clinical trials [1-3] whilst others are still under in vitro evaluation [4]. These commercially available bioreactors consist of two compartments for perfusion and cells incubation, for instance, ELAD system [5,6] and hepatassist $2000[7,8]$. There is no separate compartment for Oxygen 


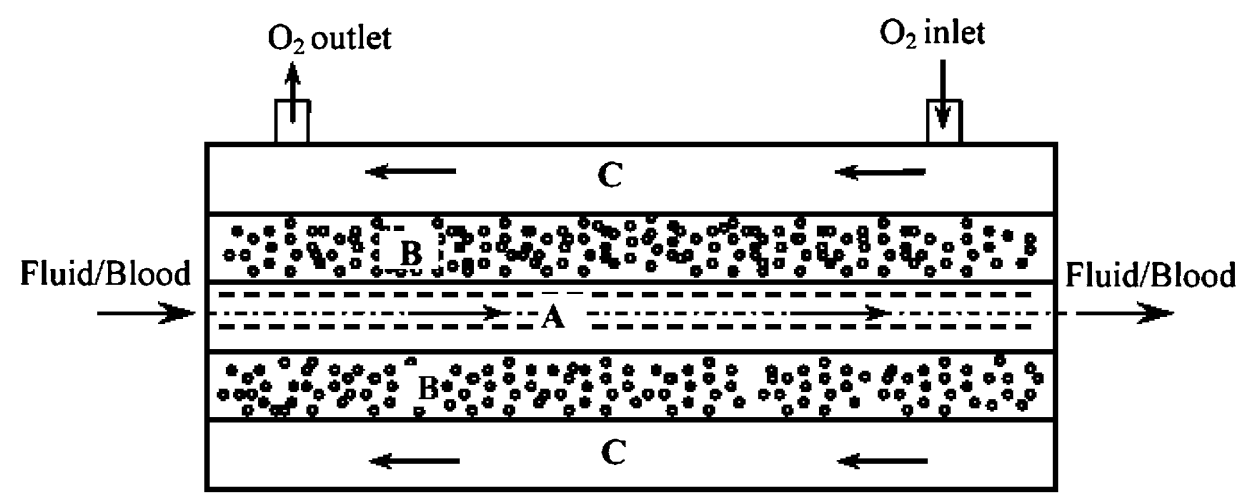

(a)

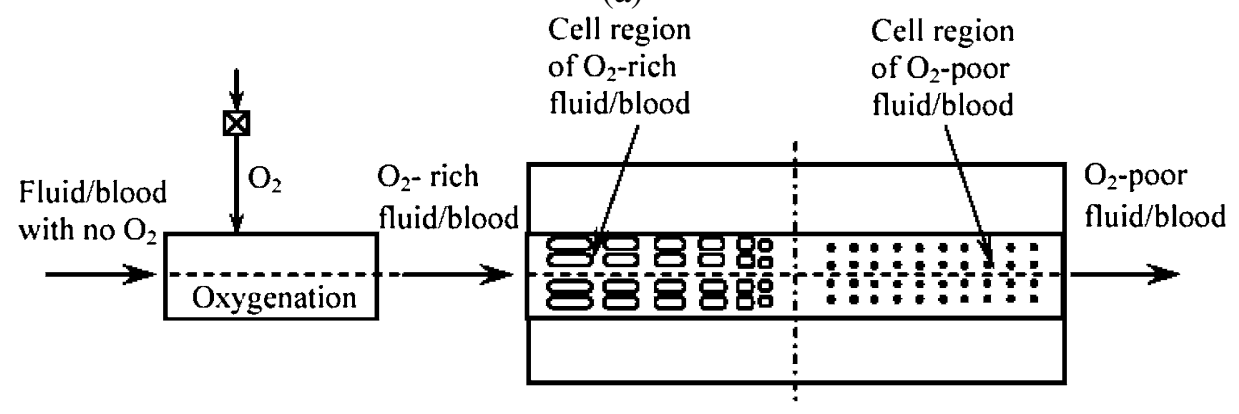

(b)

Fig. 1. Schematic drawing of (a) the newly developed bioreactor and (b) the commercially available bioreactor.

delivery within these devices. Since Oxygen diffusion is concentration driven, continues availability of Oxygen within these bioreactors is critical. Figure 1(a) shows a schematic drawing of the fluid (blood) is oxygenated externally and enters the bioreactor. In addition to its complexity as a system, most of the dissolved oxygen in the fluid (blood) will be consumed by the cells occupied at the inlet of the reactor, whereas the cells at the outlet, second $L / 2$, will have no dissolved oxygen left to be consumed. This will lead to Hypoxic conditions [9]. Exposure of hepatocytes to high $\mathrm{O}_{2}$ tension resulted in mitochondrial oxidant stress formation and massive cell death [10]. A value of $0.0024 \mathrm{nmol} \mathrm{s}^{-1} 10^{6}$ cells has been reported for a cell line embedded in gel where porcine hepatocytes giving a value of $0.083 \mathrm{nmol} \mathrm{s}{ }^{-11} 10^{6}$ cells with same configuration [11]. An alternative is coaxial (tricentric) hollow fibre bioreactors [TCHF] which contain at least a third media or gas compartment. Providing such additional compartment (oxygenation compartment, hereafter called compartment C) to the newly developed bioreactor will help to ensure that hepatocytes within more densely packed situations in the bioreactor are exposed to a continuous supply and fair distribution of oxygen (Fig. 1(b)) in which will prevent unfavourable cells responses (e.g. hypoxia). Fibre-in-fibre bioreactor (FIF) belongs to this family [12]. It consists of two hollow fibres inside each other and three compartments.

Despite the developments performed on the BAL devices, the existing systems still need to be improved and should be clinically effective. Mathematical modelling of bioreactors can be used to reduce the amount of experiment efforts necessary to a suitable operating bioreactor for cells incubation. For this, mass transfer rates of oxygen have been modelled mathematically in several studies [13-16]. To our best knowledge, no publication in literature had mathematically studied the oxygen transfer rate in TCHF devices. 
This paper focuses in modelling the Oxygen transfer rate for multi-coaxial hollow fibre bioreactors. It investigates the feasibility of using fluid equations and models of mass transport to describe the delivery of oxygen to the cell compartment. Fibre-in-fibre bioreactor is used as a model for TCHF. Oxygen transfer rate (OTR) using water as fluid from compartment $\mathrm{C}$ into the other two compartments (Compartment A and Compartment B) has been studied and reported. Despite the water has been used as working fluid in the experimental studies, authors are aware of the fact that the presence of plasma and cells will definitely change the results and the conclusion reached here. The present work also reports a comparison of the predicted and experimental oxygen transfer results to confirm the mathematical model validation and accuracy for the FIF BAL devices. The effect of modulating the Michaelis-Menten parameters $V_{\max }$ and $K$ is shown. We proceed analytically to Predict OTRs in compartments A and B in the FIF bioreactor at different flow rates and inlet oxygen concentration in compartment $\mathrm{C}$.

\section{FIF-BAL bioreactor description}

Figure 1(a)-(c) shows detailed description of the improved design of the FIF bioreactor. Schematic drawing showing the main components and geometry of the FIF bioreactor is shown in Fig. 2(a). A typical photo of the device is demonstrated in Fig. 2(b). Figure 2(c) presents schematic drawing of a crosssectional view through the FIF main bode showing the three compartments A, B and C, the inner membrane (polypropylene hollow fibre), the outer membrane (silicone-rubber hollow fibre) and the main body (outer Perspex shell). The fibres are assumed to be distributed evenly in the bioreactor. The FIF device (Figs 2 and 3) has concentric cylindrical hollow fibres HFs of length $L=130 \mathrm{~mm}$. The inner fibre is of internal radius $R_{1}=330 \mu \mathrm{m}$ and external radius $R_{2}=630 \mu \mathrm{m}$. The outer fibre has inner radius $R_{3}=1470 \mu \mathrm{m}$ and outer radius $R_{4}=1930 \mu \mathrm{m}$. The inner fibre membrane is porous so that fluid that enters the lumen (hereafter called compartment A) of each fibre can permeate across it, to or from cell region (hereafter called compartment B) at $r=R_{2}$. The cell region extends from $r=R_{2}$ to $r=R_{3}$, the inside radius of the outer fibre. It is assumed that the resistance to percolative flow through the outer fibre is relatively high so that no fluid will leak. Beyond $r=R_{4}$ is the shell space, compartment $\mathrm{C}$, which contains all the fibre pairs. It is filled with gas whose oxygen partial pressure is $P_{G}$.

In summary, each FIF bioreactor contains of three main compartments $\mathrm{A}, \mathrm{B}$ and $\mathrm{C}$ as follow:

1. Compartment $\mathrm{A}$, for which $0.0 \leqslant r \leqslant R_{1}$ and $0 \leqslant z \leqslant L$.

2. Compartment B (annulus or cell region), for which $R_{2} \leqslant r \leqslant R_{3}$.

3. Compartment $\mathrm{C}$, gas diffusion zone for which, $r>R_{4}$.

\section{Methods}

Oxygen partial pressure $P$ in both Compartments $\mathrm{A}$ and $\mathrm{B}$ is measured using a fluid gas analyzer (Rapidlab $^{\mathrm{TM}} 248 \mathrm{pH} / \mathrm{blood}$, gas analyser). The bioreactor consists of either 13 or 19 FIF pairs with total working length of $130 \mathrm{~mm}$. During the operation of the bioreactor, fluid is passed through compartment $\mathrm{A}$, while oxygen is pumped through compartment $\mathrm{C}$. Since the bioreactor has not been tested yet with cells, the $V_{\max }$ maximum rate of $\mathrm{O}_{2}$ consumption per unit volume in compartment B was obtained from literature. Upper and lower estimates of the $V_{\max }$ of $20 \mathrm{nmol} \mathrm{s}^{-1} \mathrm{~cm}^{-3}$ and $2 \mathrm{nmol} \mathrm{s}^{-1} \mathrm{~cm}^{-3}$, respectively, were used in the theoretical calculations. Darcy's constant for fluid percolation, $K_{m}$, value was determined from the experimental work. Quality assurance was performed during the bioreactor assembly as described by Hilal-Alnaqbi [12]. For mathematical model validation, two sets of experiments 


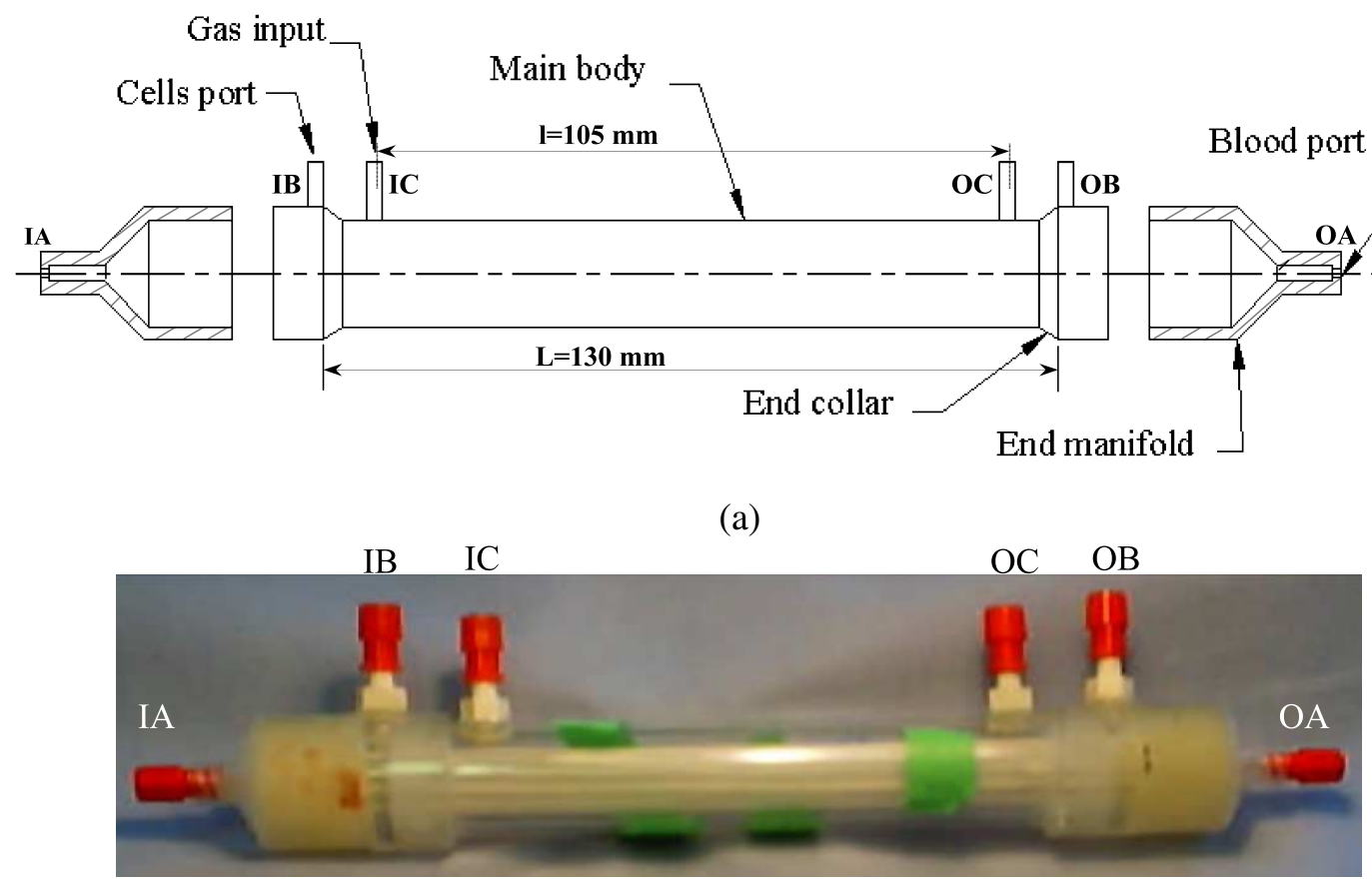

(b)

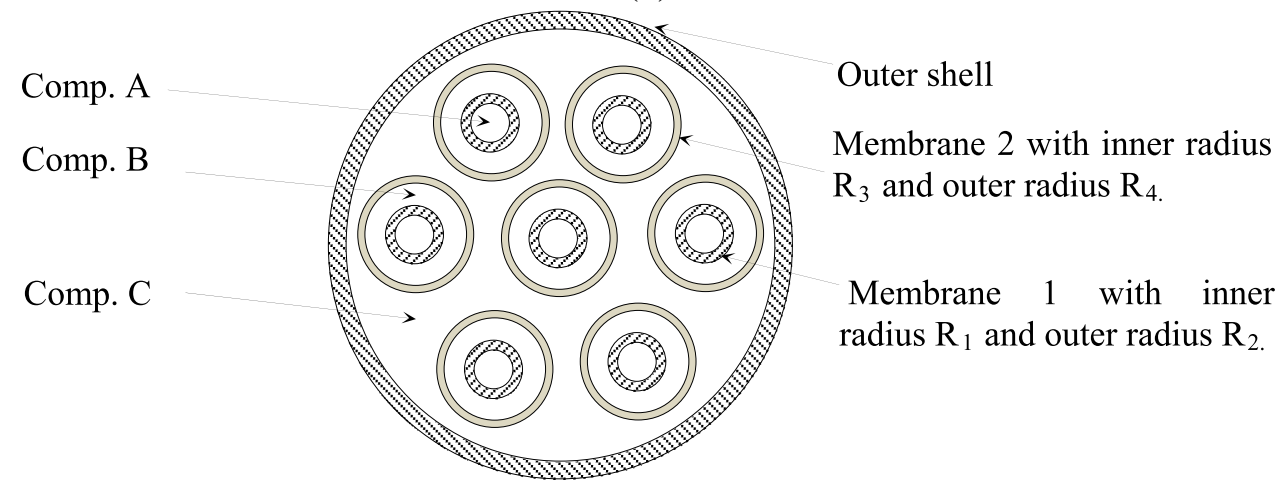

(c)

Fig. 2. (a) Schematic drawing of the FIF bioreactor. (b) Photo of the FIF bioreactor. (c) Schematic of the cross-sectional view of the FIF Bioreactor main body showing the membranes 1 and 2, the compartments A, B and C and the outer shell. (Colors are visible in the online version of the article; http://dx.doi.org/10.3233/BME-130762.)

were performed. These are oxygen transfer rate OTR in compartments A and B and the transmembrane pressure drop experiments.

\section{Experiments}

The widely accepted $28 \%$ gas mixture is used for oxygen transfer rate OTR experiments. The gases mixture transfers from compartment $\mathrm{C}$, of higher oxygen partial pressure, to compartments $\mathrm{B}$ and $\mathrm{A}$, of lower oxygen partial pressure. The relationship between the flow rate $Q$ and the hydrostatic pressure 


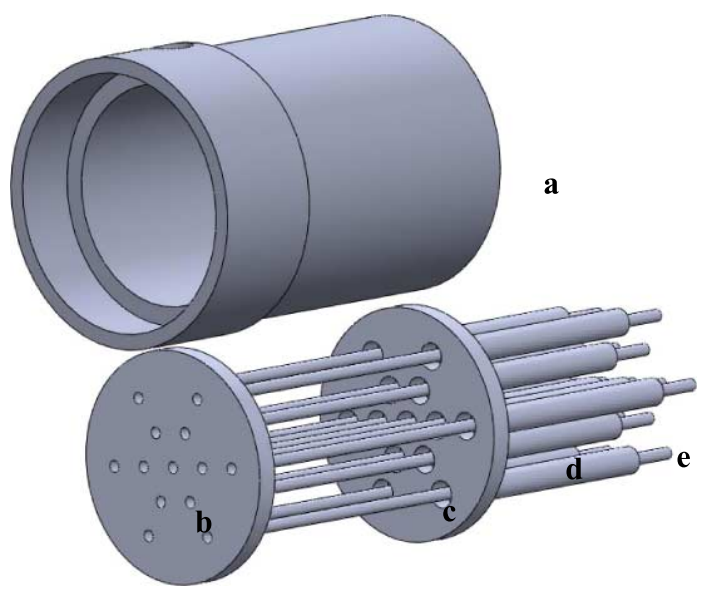

Fig. 3. Improved FIF bioreactor design: (a) main body (outer Perspex shell); (b) polypropylene HF guide plate; (c) silicone rubber HF guide plate; (d) silicone rubber membrane; (e) plasmapheresis membrane. (Colors are visible in the online version of the article; http://dx.doi.org/10.3233/BME-130762.)

$\mathrm{P}$ can predict the hydraulic characteristics of the compartments. The results and findings from these experiments are used to validate the proposed mathematical model.

The $\mathrm{O}_{2}$ free nitrogen gas was bubbled slowly $(200 \mathrm{ml} / \mathrm{min})$ into a reservoir containing ultrafiltered water until the oxygen partial pressure $P_{\mathrm{O}_{2}, o}$ was approximately of 2-3 $\mathrm{kPa}$ value. The deoxygenated water was then carefully transferred to a $50 \mathrm{ml}$ syringe mounted on a syringe pump. Always $1 \mathrm{ml}$ sample was taken for a $P_{\mathrm{O}_{2}, i}$ check and experiments were repeated 5 times. The Rapidlab ${ }^{\mathrm{TM}} 248 \mathrm{pH} / \mathrm{Blood}$ Gas Analyser was used to measure the samples inlet oxygen partial pressure $\left(P_{\mathrm{O}_{2}, i}\right)$ and outlet oxygen partial pressure $\left(P_{\mathrm{O}_{2}, o}\right)$, respectively. The bioreactor and syringe pump were placed in an incubator set at $37^{\circ} \mathrm{C}$. The measurement of the water flow rate $Q$ was carried out by timed volumetric collection into a graduated pipette to validate nominal flow rate settings of the syringe pump.

The oxygen transfer OTR rate has been calculated using the following equation:

$$
\mathrm{OTR}=\left(P_{\mathrm{O}_{2}, o}-P_{\mathrm{O}_{2}, i}\right) Q \alpha_{o}(\mathrm{nmol} / \mathrm{h}),
$$

where OTR is oxygen transfer rate, $P_{\mathrm{O}_{2}, o}$ is the outlet oxygen partial pressure $(\mathrm{mmHg}) ; P_{\mathrm{O}_{2}, i}$ is the inlet oxygen partial pressure $(\mathrm{mmHg}), Q$ is the water flow rate $(\mathrm{ml} / \mathrm{h}) ; \alpha_{o}\left(\mathrm{nmol} / \mathrm{cm}^{3} \mathrm{mmHg}\right)$ is the solubility of $\mathrm{O}_{2}$ in water at $37^{\circ} \mathrm{C}$.

The pressure drops over the compartment length were measured for varying flow rates of distilled water through the compartments A and B. The pressure was measured at inlet and outlet of the tested compartment with the other compartment (untested) filled with water and sealed.

\section{Mathematical modelling}

\subsection{Fluid equations}

A mathematical model is only as good as the assumptions on which it is based. The FIF bioreactor device is recognised as a hollow fibre bioreactor and treated as a parallel array of uniformly spaced compartments by using the guiding plates in the device (Fig. 3). The proposed mathematical model is 
for a single fibre and associated cell mass $V_{\max }$. Fluid is pumped into compartment $\mathrm{A}$ at feed flow rate $q_{1}$ and viscosity $\eta$. The model uses an axial coordinate $z$ running from compartment A inlet at $z=0$ to compartment A outlet at $z=L$, the length of the FIF bioreactor (Fig. 2(a)). In the model, the fluid flow rate and pressure are donated by $q$ and $p$, with subscripts $l, c$ and $G$ denoting compartment A, annulus (cells compartment, hereafter called compartment B) and oxygenation compartment (compartment C), respectively. Therefore, the partial pressure of oxygen are donated by $P_{l}, P_{c}$ and $P_{G}$, fluid pressure at $z$ in compartment $\mathrm{A}$, fluid pressure at $z$ in cells compartment $\mathrm{B}$ and oxygen partial pressure in gas compartment C, respectively. The fluid flow calculation for this device is similar to that in Hay et al. [15] that is Poiseuille flow in a tube of inner radius $R_{1}$ has a volume flow rate of

$$
q_{l}=\pi R_{1}^{4}\left(-\mathrm{d} P_{l} / \mathrm{d} z\right) /(8 \eta)
$$

where $q_{l}$ is the fluid volume flow rate at $z$ in compartment $\mathrm{A} ; R_{1}$ is the internal radius of the inner fibre; $P_{l}$ is the fluid pressure at $z$ in compartment $\mathrm{A}$; and $\eta$ is the viscosity coefficient of the fluid. Here, $q_{l}$ varies with the axial coordinate $z$, as fluid leaks out of the compartment A into compartment $\mathrm{B}$, and eventually back into compartment $\mathrm{A}$. This pressure variation in compartment $\mathrm{A}$ with $z$ can be expressed as:

$$
\frac{\mathrm{d} P_{l}}{\mathrm{~d} z}=-\frac{8 \eta\left(q_{o}-q_{c}\right)}{\pi R_{1}^{4}} .
$$

In the cells region (compartment B) the flow is modelled as a percolating flow through the cells, described by the following Darcy's differential equation

$$
k_{c}\left(-\mathrm{d} P_{c} / \mathrm{d} z\right)=\eta v_{c}=\eta q_{c} /\left\{\pi\left(R_{3}^{2}-R_{2}^{2}\right)\right\}
$$

which can be written as

$$
\frac{\mathrm{d} P_{c}}{\mathrm{~d} z}=-\frac{\eta q_{c}}{\pi k_{c}\left(R_{3}^{2}-R_{2}^{2}\right)}
$$

There is a pressure difference across the inner membrane, and this drives the feed to percolate through membrane wall and ultimately back again. This percolation is modelled as a Darcy flow with Darcy constant $k_{m}$. The hydraulic permeability $k_{c}$ for cell compartment (compartment B) will vary depending on cell type and density. It is difficult to ascertain $k_{c}$ since the bioreactor was not tested with cells. In literature, most researchers use values between $10^{-4}$ and $10^{-8}[9,17]$. For the model validation, a value of $10^{-7}$ has been considered here. Whereas the most direct way of obtaining the hydraulic permeability of the plasmapheresis membrane $k_{m}$ was to create a radial flow through the inner fibre from the compartment A at fluid pressure $P_{l}$ to the cell compartment at fluid pressure $P_{c}$ driving a total volume flow rate $Q$ through the fibre. The following equation is derived using Eqs (4)-(6) of Hay et al. [9] model

$$
k_{m}=\frac{Q \eta \ln \left(R_{2} / R_{1}\right)}{2 \pi L\left(P_{l}-P_{c}\right)},
$$


where $\eta$ is the fluid viscosity. As the fluid leakage increases into the cells region, we have $\mathrm{d} q_{c}=$ $2 \pi R_{2} \mathrm{~d} z v R_{2}$, and then,

$$
\frac{\mathrm{d} q_{c}}{\mathrm{~d} z}=\frac{2 \pi k_{m}\left(P_{l}-P_{c}\right)}{\eta \ln \left(R_{2} / R_{1}\right)} .
$$

Three simultaneous linear differential equations were derived for $P_{l}, P_{c}$ and $q_{c}$. In principle the following three initial conditions at $z=0$ and $z=L$ are needed to solve these equations:

(a) $P_{l}=P_{o}$ at $z=0$,

(b) $q_{c}=\varepsilon q_{o}$, at $z=0$,

(c) $q_{c}=\varepsilon q_{o}$, at $z=L$.

It is more natural to put $q_{c}=0$ at $z=0$ and $z=L$; and from the fluid flow point of view there is nothing wrong with this. However in the subsequent oxygen transfer calculations there is a technical difficulty that arises in the model if $q_{c}$ becomes zero at any point along the device. The use of a small value of $\varepsilon q_{0}$ at $z=0$ gives a work around for this difficulty; and using the same value at $z=L$ allows us to maintain a convenient mirror symmetry of the fluid flow solution about $z=L / 2$.

The oxygen mass consumption rate (OCR) per unit volume of the hepatocytes cells modelled using Michaelis-Menten kinetics $[9,17,18]$ which states that OCR $=V_{\max } p /(p+K)$, where $V_{\max }$ is the maximum rate of oxygen consumption per unit volume of the cells, and $K$ is $V_{\max } / 2$ (in the case with no cells, $V_{\max }=0$ ).

\subsection{Oxygen consumption rate differential equations}

As $q_{c}$ increases with $z$, the oxygen transfer rate balance for a section $\mathrm{d} z$ of compartment $\mathrm{B}$ is given by

$$
\alpha p q_{c}+\alpha p_{0} \mathrm{~d} q_{c}+\alpha \mu\left(p_{G}-p\right) \mathrm{d} z=\alpha(p+\mathrm{d} p)\left(q_{c}+\mathrm{d} q_{c}\right)+\alpha \lambda p \mathrm{~d} z /(p+K) .
$$

Cancelling $\alpha$, neglecting $\mathrm{d} p \cdot \mathrm{d} q_{o}$ and rearranging gives,

$$
\frac{\mathrm{d} p}{\mathrm{~d} z}=\frac{\left(p_{0}-p\right) \mathrm{d} q_{c} / \mathrm{d} z-\lambda p /(p+K)+\mu\left(p_{G}-p\right)}{q_{c}}=f(z, p) .
$$

As $q_{c}$ decreases with $z$, the balance is given by

$$
\alpha p q_{c}+\alpha \mu\left(p_{G}-p\right) \mathrm{d} z=\alpha(p+\mathrm{d} p)\left(q_{c}+\mathrm{d} q_{c}\right)+\alpha p\left(-\mathrm{d} q_{c}\right)+\alpha \lambda p \mathrm{~d} z /(p+K) .
$$

Cancelling similar terms and rearranging gives

$$
\frac{\mathrm{d} p}{\mathrm{~d} z}=\frac{-\lambda p /(p+K)+\mu\left(p_{G}-p\right)}{q_{c}}=g(z, p) .
$$

From an initial condition for $P$ at $z=0$, a numerical procedure is used to obtain the solution in steps using $\mathrm{d} P / \mathrm{d} z=f(z, P)$ until $\mathrm{d} q_{c} / \mathrm{d} z$ changes sign from positive to negative. From the value of $P$ nearest to $\mathrm{d} q_{c}=0$. The solution is continued using $\mathrm{d} P / \mathrm{d} z=g(z, P)$ until the end of the device is reached. This gives the axial partial pressure profile in the cell region. The Matlab built in code ODE45 is used to numerically solve the differential equations. 


\section{Results}

\subsection{Experimental measurements}

\subsubsection{Oxygen transfer rate}

The Fibre-in-fibre FIF bioreactor was developed to accommodate different cell types such as liver cells and the highest degree of precautions possible was considered in designing. Table 1 presents sample of the experimental findings of outlet oxygen partial pressure $P_{\mathrm{O}_{2}, o}$ for different values of water flow rate $Q$ $(40,70,90$ and $160 \mathrm{ml} / \mathrm{h})$ and controlled inlet oxygen partial pressure $P_{\mathrm{O}_{2}, i}$ of around $3 \mathrm{kPa}$ for $19 \mathrm{FIF}$ bioreactor module. The results indicate that the maximum deviation of outlet oxygen partial pressure $P_{\mathrm{O}_{2}, o}$ from the average for all tests was $15 \%$.

Table 2 presents the values of the OTR that are calculated from Eq. (1) using the data presented in Table 1. The values of OTR are calculated for 19 FIF and 13 FIF modules in both compartments A and B. For the purpose of finding OTR, oxygen solubility $\alpha_{\mathrm{o}}$ in water at $37^{\circ} \mathrm{C}$ of $10.6 \mathrm{nmol} / \mathrm{ml} \mathrm{kPa}$ was used. Figure 4 shows that the 13 FIF bioreactor has a higher OTR than that of the 19 FIF bioreactor for all the flow rates except for $40 \mathrm{ml} / \mathrm{h}$. As the flow rate $Q$ increases in both bioreactor modules, the OTR increases except for flow rate of $90 \mathrm{ml} / \mathrm{h}$.

Results and graphs of oxygen outlet partial pressure $P_{\mathrm{O}_{2}, o}$ versus time for both 13 and 19 FIF bioreactors for the tested flow rates are given in Fig. 5. Results for most of the experiments, show that the $P_{\mathrm{O}_{2}, o}$ is unstable for the first few seconds after gas circulating in compartment C. After approximately $1 \mathrm{~min}$ the $P_{\mathrm{O}_{2}, o}$ increases rapidly prior the curve reaches its plateau after approximately $10 \mathrm{~min}$ of the perfu-

Table 1

\begin{tabular}{lccc} 
The average of three $P_{\mathrm{O}_{2}, o}$ readings for four different $Q$ and controlled $P_{\mathrm{O}_{2}, i}(\sim 3 \mathrm{kPa})$ \\
\hline Module number & $Q(\mathrm{ml} / \mathrm{h})$ & $P_{\mathrm{O}_{2}, i}(\mathrm{kPa})$ & $P_{\mathrm{O}_{2}, o}(\mathrm{kPa})$ \\
\hline 1 & 40 & 3.11 & 21.81 \\
& 70 & 3.83 & 15.9 \\
& 90 & 3.43 & 23.64 \\
& 160 & 3.23 & 21.95 \\
40 & 2.7 & 21.94 \\
& 70 & 3.06 & 20.44 \\
& 90 & 3.07 & 22.6 \\
& 160 & 3.72 & 22.47 \\
40 & 3.41 & 23.16 \\
3 & 70 & 3.9 & 24.14 \\
& 30 & 3.53 & 23.46 \\
& 160 & 3.93 & 22.91 \\
40 & 3.03 & 21.47 \\
4 & 70 & 2.98 & 24.65 \\
& 90 & 2.68 & 24.67 \\
& 160 & 3.57 & 24.02 \\
40 & 4.09 & 17.87 \\
70 & 3.29 & 19.07 \\
5 & 3.14 & 23.65 \\
& 160 & 21.07 \\
\hline
\end{tabular}

Note: The results are obtained from five different bioreactors of 19 FIF model with axial flow in compartment $B$. 
Table 2

The average OTR of 5 bioreactors readings calculated using Eq. (2) and data presented in Table 1

\begin{tabular}{ccccc}
\hline $\begin{array}{c}\text { Case } \\
Q(\mathrm{ml} / \mathrm{h})\end{array}$ & $\begin{array}{c}\text { OTR-19 FIF } \\
\text { (Comp. A) }\end{array}$ & $\begin{array}{c}\text { OTR-19 FIF } \\
\text { (Comp. B) }\end{array}$ & $\begin{array}{c}\text { OTR-13 FIF } \\
\text { (Comp. A) }\end{array}$ & $\begin{array}{c}\text { OTR-13 FIF } \\
\text { (Comp. B) }\end{array}$ \\
\hline 40 & 138 & 122.5 & 135 & 142 \\
70 & 217.4 & 234 & 206 & 233.7 \\
90 & 297.8 & 332.7 & 302 & 311 \\
160 & 529.4 & 562 & 521 & 531 \\
\hline
\end{tabular}

Note: The OTR average values are obtained using four different bioreactors models with for different axial flow rates.

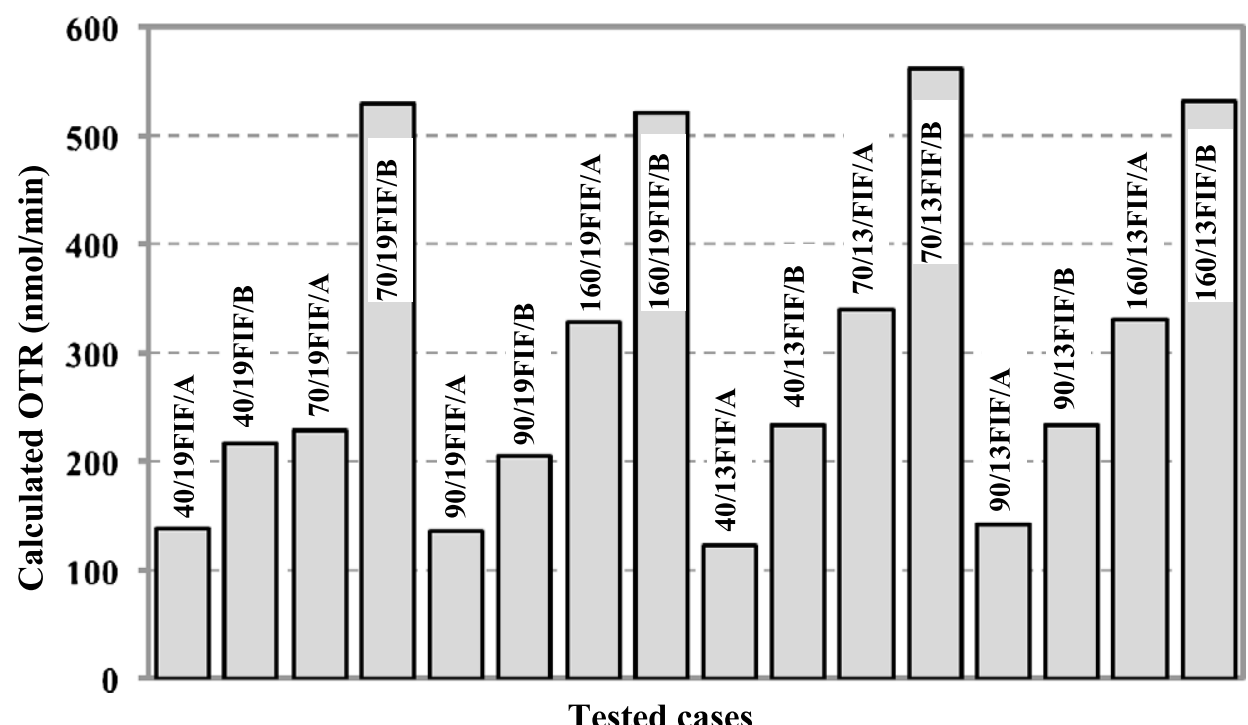

Fig. 4. Calculated OTR from the experimental work on the 13 FIF and 19 FIF bioreactors. The key legend denotes the module size, the compartment with water flow and the flow rate, e.g. 40/19FIF/B is an experiment with a 19 fibre set bioreactor, water flow in compartment $\mathrm{B}$ and a flow rate of $40 \mathrm{ml} / \mathrm{h}$.

sion indicating the attainment of the saturation/equilibrium condition. This increase is more noticeable at high flow rate.

\subsubsection{Hydrostatic pressure drop}

The results of hydrostatic pressure $P$ versus flow rate $Q$ for the 19 and 13 FIF bioreactors are examined and plotted in Fig. 6. This figure shows that pressure drop varies linearly with axial flow rate in the bioreactor compartments. It is not only that, but also showed that compartment A in both 13 and 19 FIF modules giving a higher pressure drop than that noticed in compartment B with the same flow rate.

\section{Mathematical model results}

\subsection{Model accuracy evaluation}

The obtained data from experimental work of OTR was used to validate the proposed model in predicting oxygen transfer. The model is applied under non cellular condition to mimic the experimental tests 


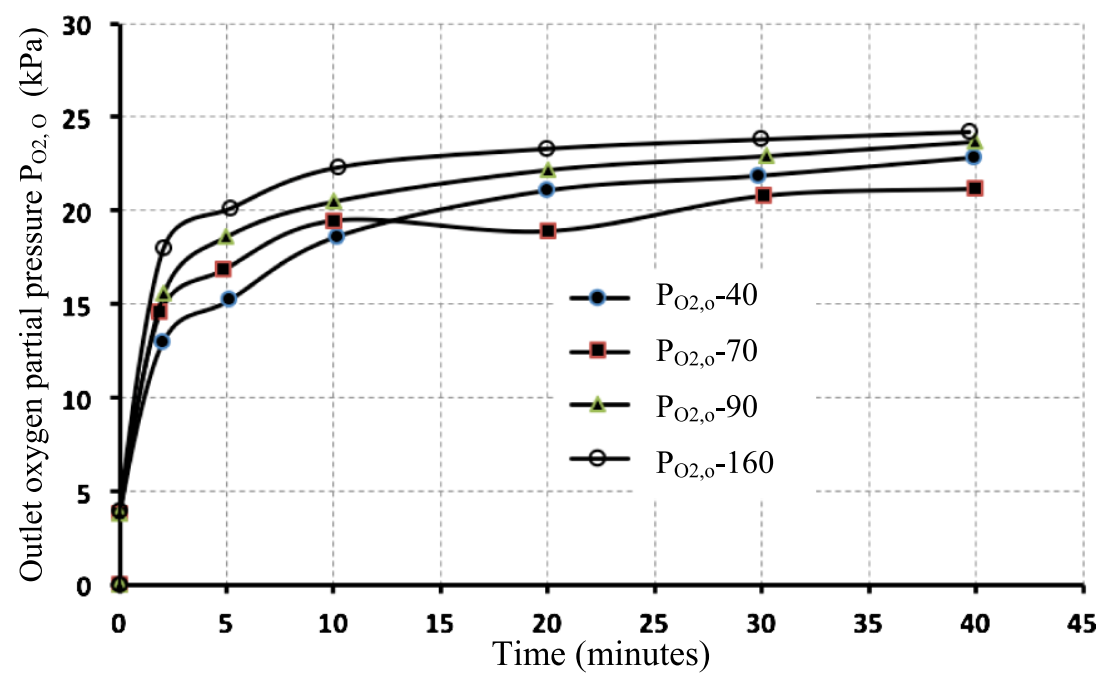

(a)

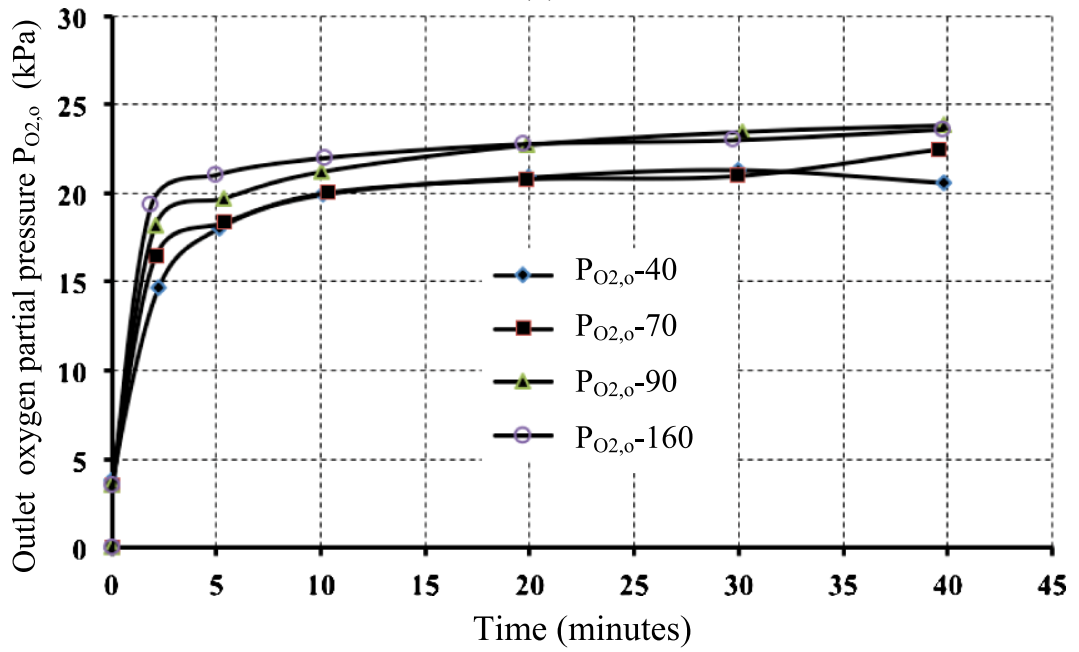

(b)

Fig. 5. Outlet oxygen partial pressure $P_{\mathrm{O}_{2}, o}$ versus time of perfusion for $40-160 \mathrm{ml} / \mathrm{h}$ flow rates. (a) 19 FIF bioreactor and perfusion in the compartment A. (b) 19 FIF bioreactor and perfusion in the compartment B. (Colors are visible in the online version of the article; http://dx.doi.org/10.3233/BME-130762.)

conditions described in the methodology section. A general listing of the input parameters for the computer implementation are presented in Table 3. These parameters were either determined by independent experiments or obtained from the literature as summarized in the table. Literature survey was conducted to get values for $V_{\max }$ and half saturation constant $K$. Because of the literature values is likely to be accompanied with other factors including culture configuration and density of the cells, we chose to use Hay's et al. [9] values of lower and upper bounds for $V_{\max }$ are 10 and $25 \mathrm{nmol} \mathrm{s}^{-1} \mathrm{~cm}^{-3}$, respectively.

The model predictions were compared with OTR experimental data in Fig. 7. At each flow rate, four bars are displayed. Two of these bars represent predicted values and the other two bars represent the corresponding experimental data. Experimental and predicted results show that the OTR increases with increasing liquid flow rate. The results also show that the model slightly over-predict the experimental 


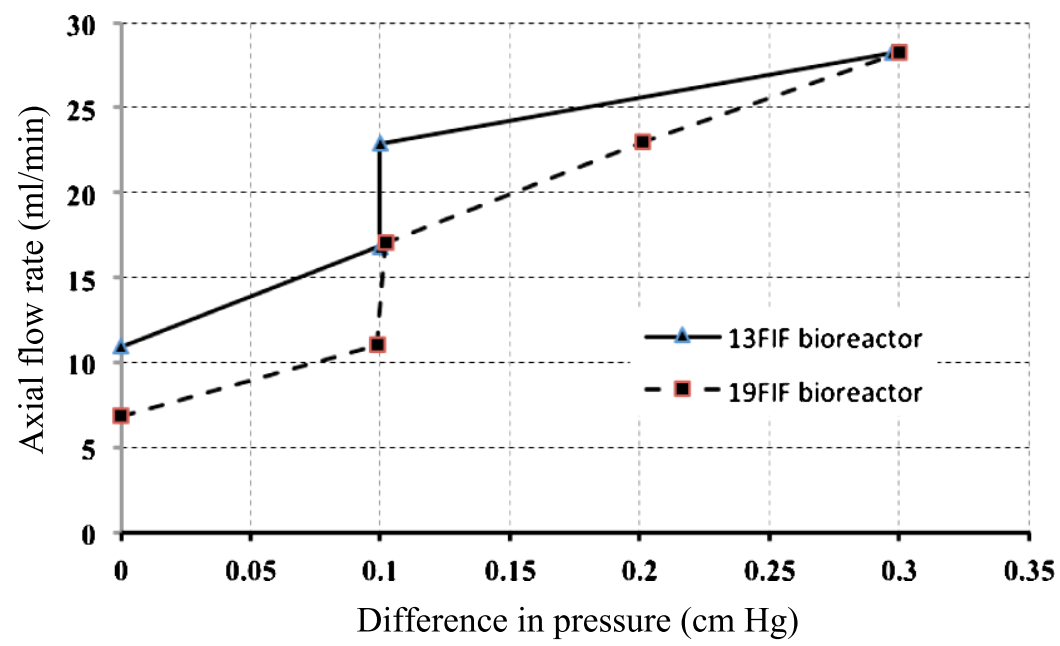

(a)

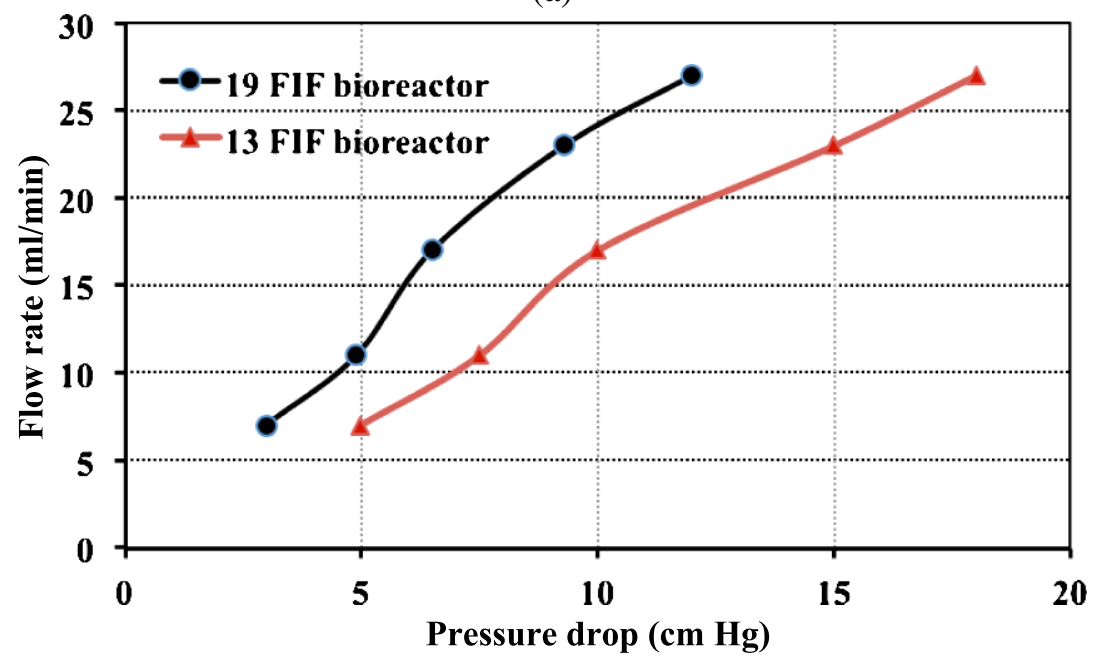

(b)

Fig. 6. (a) Axial flow rate of water versus pressure drop in compartment B for both 13 FIF and 19 FIF bioreactors. (b) Axial flow rate of water versus pressure drop for compartment A for both 13 FIF and 19 FIF bioreactors. (Colors are visible in the online version of the article; http://dx.doi.org/10.3233/BME-130762.)

Table 3

Input parameters for OTR and hydraulic pressure drop predictions using water as perfusate in compartment A

\begin{tabular}{lll}
\hline Parameter & \multicolumn{1}{c}{ Value } & \multicolumn{1}{c}{ Source } \\
\hline Flow rate & $0.6,1.2,1.5,2.7 \mathrm{~cm}^{3} / \mathrm{min}$ & OTR experiments \\
Viscosity of water at $37^{\circ} \mathrm{C}$, used for OTR predictions & $0.0006915(\mathrm{~Pa} \cdot \mathrm{s})$ & Chemistry and physics handbook \\
Viscosity of water at $25^{\circ} \mathrm{C}$, used for pressure & $0.0008904(\mathrm{~Pa} \cdot \mathrm{s})$ & Chemistry and physics handbook \\
drop predictions & & \\
$\mathrm{O}_{2}$ solubility in water $\left(\alpha \mathrm{O}_{2}\right)$ & $1.415 \mathrm{nmol} /\left(\mathrm{cm}^{3} \mathrm{mmHg}\right)$ & {$[19,20]$} \\
$V_{\max }$ & $20 \mathrm{nmol} \mathrm{s} \mathrm{cm}^{-3}$ and a lower & Literature \\
& value of $2 \mathrm{nmol} \mathrm{s}^{-1} \mathrm{~cm}^{-3}$ & \\
\hline
\end{tabular}




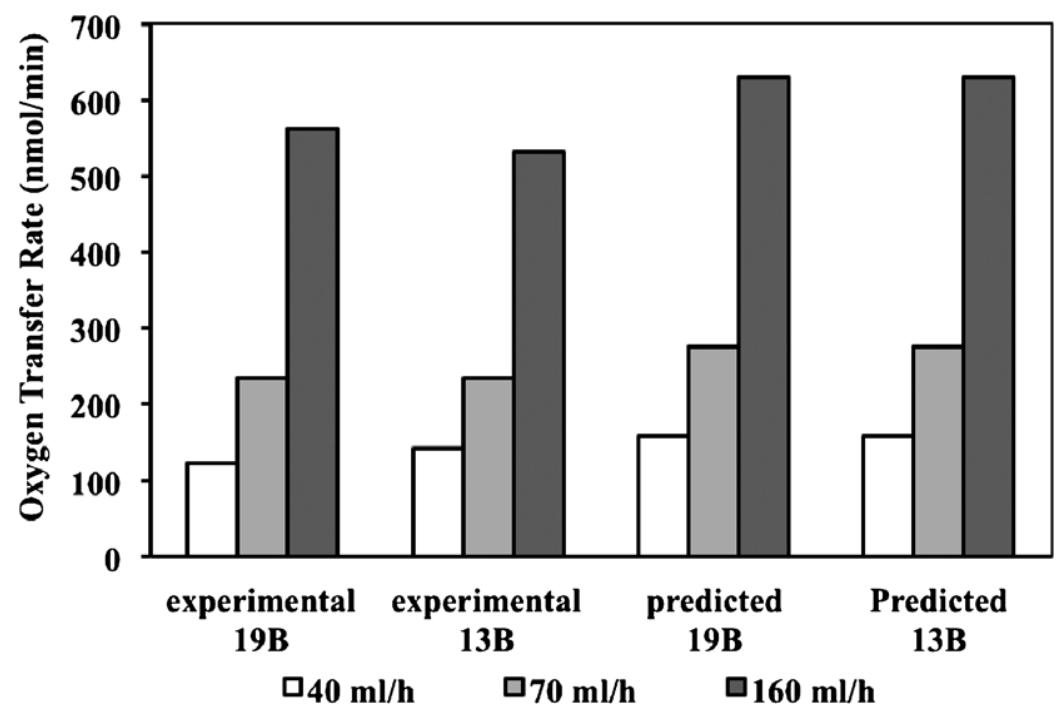

Fig. 7. Experimental and predicted OTRs in compartment B for 13 FIF and 19 FIF bioreactor modules for 40, 70 and $160 \mathrm{ml} / \mathrm{h}$ flow rates.

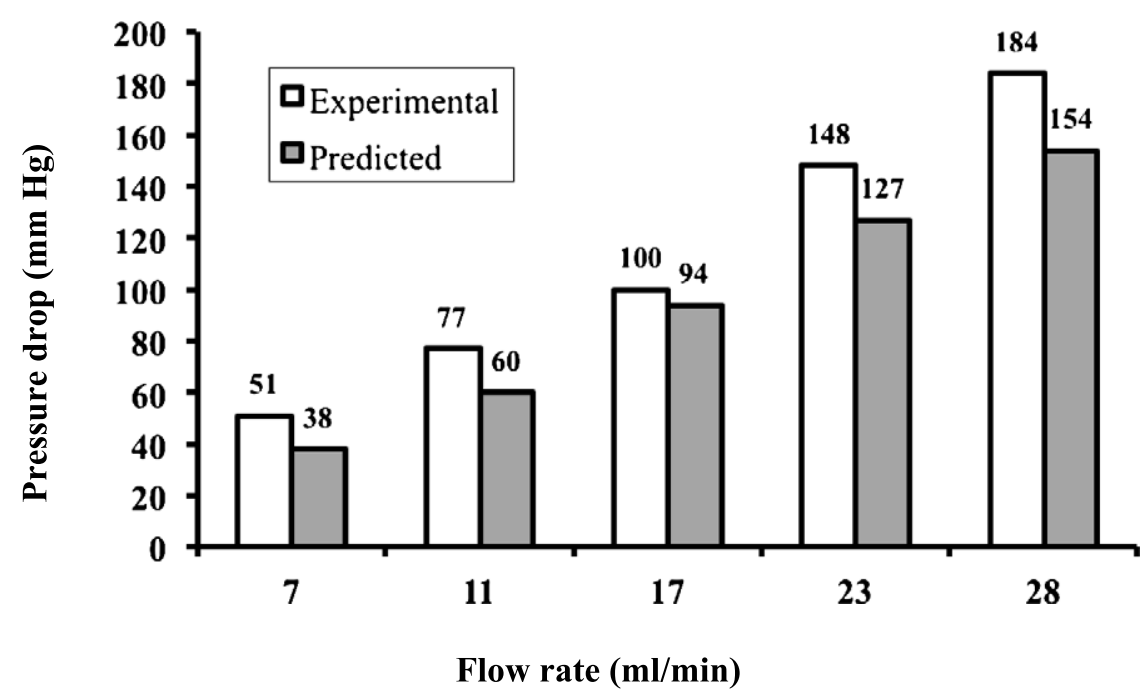

Fig. 8. Experimental and predicted pressure drop in the 13 FIF bioreactor for 5 different water flow rates at room temperature $\left(25^{\circ} \mathrm{C}\right) .\left(L=13 \mathrm{~cm}, K_{m}=2.2 \times 10^{-11} \mathrm{~cm}^{2}, \eta=0.0008904 \mathrm{~Pa} \cdot \mathrm{s}.\right)$

OTR by maximum $12 \%$. Such over prediction is also reported by Hay et al. [9]. The best match to experimental data is found with higher number of FIF pairs. The over-prediction is expected since the model has assumptions for perfect operation mode. There is no correlation between the flow rate and the magnitude of the over-prediction. The experimental results indicate that the OTR in 13 FIF module is not significantly different from that in the 19 FIF module. The OTRs predicted by the model clearly support this experimental observation, where for each flow rate the theoretical OTRs were the same irrespective of the number of fibre in fibre pairs in the bioreactor.

Figure 8 shows the predicted hydraulic pressure drop compared with experimental values along the fibre length at room temperature for the 13 FIF bioreactor module with water flow rates of $7,11,17$, 
Table 4

Input parameters for OTR predictions using plasma as perfusate in compartment A

\begin{tabular}{lccc}
\hline Parameter & Value & Unit & Sources \\
\hline Flow rate $q_{0}$ per fibre for 13 FIF & $0.00085-0.00346$ & $\mathrm{~cm}^{3} / \mathrm{min}$ & - \\
Flow rate $q_{0}$ per fibre for 19 FIF & $0.00058-0.00233$ & $\mathrm{~cm}^{3} / \mathrm{min}$ & - \\
Viscosity of plasma at $37^{\circ} \mathrm{C}$ & 0.00118 & $\mathrm{~Pa} \cdot \mathrm{s}$ & Chemistry and physics handbook \\
$\mathrm{O}_{2}$ solubility in plasma, $\alpha_{\mathrm{O}_{2}}$ & 1.19 & $\mathrm{nmol} /\left(\mathrm{cm}^{3} \mathrm{mmHg}\right)$ & {$[9]$} \\
Hydraulic permeability in compartment B, $K_{c}$ & $10^{-4}-10^{-8}$ & $\mathrm{~cm}^{2}$ & {$[9,17]$} \\
\hline
\end{tabular}

23 and $28 \mathrm{ml} / \mathrm{min}$. Polypropylene permeability of $K_{m}=2.2 \times 10^{-11} \mathrm{~cm}^{2}$ was used for the model prediction. The results show that in both predicted and experimental data illustrate that the pressure drop increases as the flow rate rises. The results also show that there is a little underestimation in the pressure drop by maximum $6 \%$ as compared to the experimental values. These findings are supported by Hay et al. [9] results and are expected since the experimental results are affected by the operation practice. A flow rate of $17 \mathrm{ml} / \mathrm{min}$ results in the best match between the predicted $(94 \mathrm{mmHg}$ ) and the experimental $(100 \mathrm{mmHg})$ pressure drop values. At lower flow rates, there is a less agreement between the predicted and experimental results. Differences of $26 \%$ and $22 \%$ are found at flow rates of 7 and $11 \mathrm{ml} / \mathrm{min}$, respectively. The developed model in this work shows a better accuracy than that reported by Hay et al. [9]. They showed underestimations of $37 \%, 45 \%$ and $72 \%$ in the predicted OTR values for flow rates of $100 \mathrm{~cm}^{3} / \mathrm{min}, 200 \mathrm{~cm}^{3} / \mathrm{min}$ and $400 \mathrm{~cm}^{3} / \mathrm{min}$, respectively, when comparing with the experimental results. Generally, the findings of the developed model illustrate good model accuracy in predicting the OTR at different flow rates.

\subsection{OTR using plasma}

In order to find the effect of oxygen concentration on the OTR from compartment $\mathrm{C}$ to compartment $\mathrm{B}$, three different oxygen concentrations were used. The input parameters used for this study are presented in Tables 3 and 4. Figure 9 shows the OTR results; each oxygen concentration has four bars. Each bar represents a different flow rate of plasma in compartment $\mathrm{A}$. The results show clearly an increase in the OTR as flow rate increases. For the same flow rate, the OTR increases with oxygen concentration as expected. The OTR increases from $35 \mathrm{nmol} / \mathrm{s}$ for $20 \% \mathrm{O}_{2}$ to $162 \mathrm{nmol} / \mathrm{s}$ for $70 \% \mathrm{O}_{2}$ at a plasma flow rate of $17 \mathrm{ml} / \mathrm{min}$ and from $739 \mathrm{nmol} / \mathrm{s}$ for $20 \% \mathrm{O}_{2}$ to $3384 \mathrm{nmol} / \mathrm{s}$ for $70 \% \mathrm{O}_{2}$ for a plasma flow rate of $400 \mathrm{ml} / \mathrm{min}$. The OTR increases by 4.5 fold when $\mathrm{O}_{2}$ concentration increases from $20 \%$ to $70 \%$.

\section{Discussion}

In this paper a new bioartificial BAL device consists of three compartments was designed with integral oxygenation in the outermost compartment to secure the oxygen supply to the cells in compartment B. A total of 10 bioreactors were used to study the OTR in the FIF bioreactor. The results show that the OTR values for the 19 FIF modules are not significantly different from those obtained for the 13 FIF despite a $45 \%$ increase in surface area (Table 2). This observation was true for all flow rates and would indicate that the perfusate was saturated with $\mathrm{O}_{2}$ at the compartment outlet, regardless to the number of FIF pairs.

Another experimental observation is that the OTR from compartment $\mathrm{C}$ to compartment $\mathrm{B}$ is relatively greater than that in compartment $\mathrm{A}$. This is due to the distance involved in the mass transferring from 


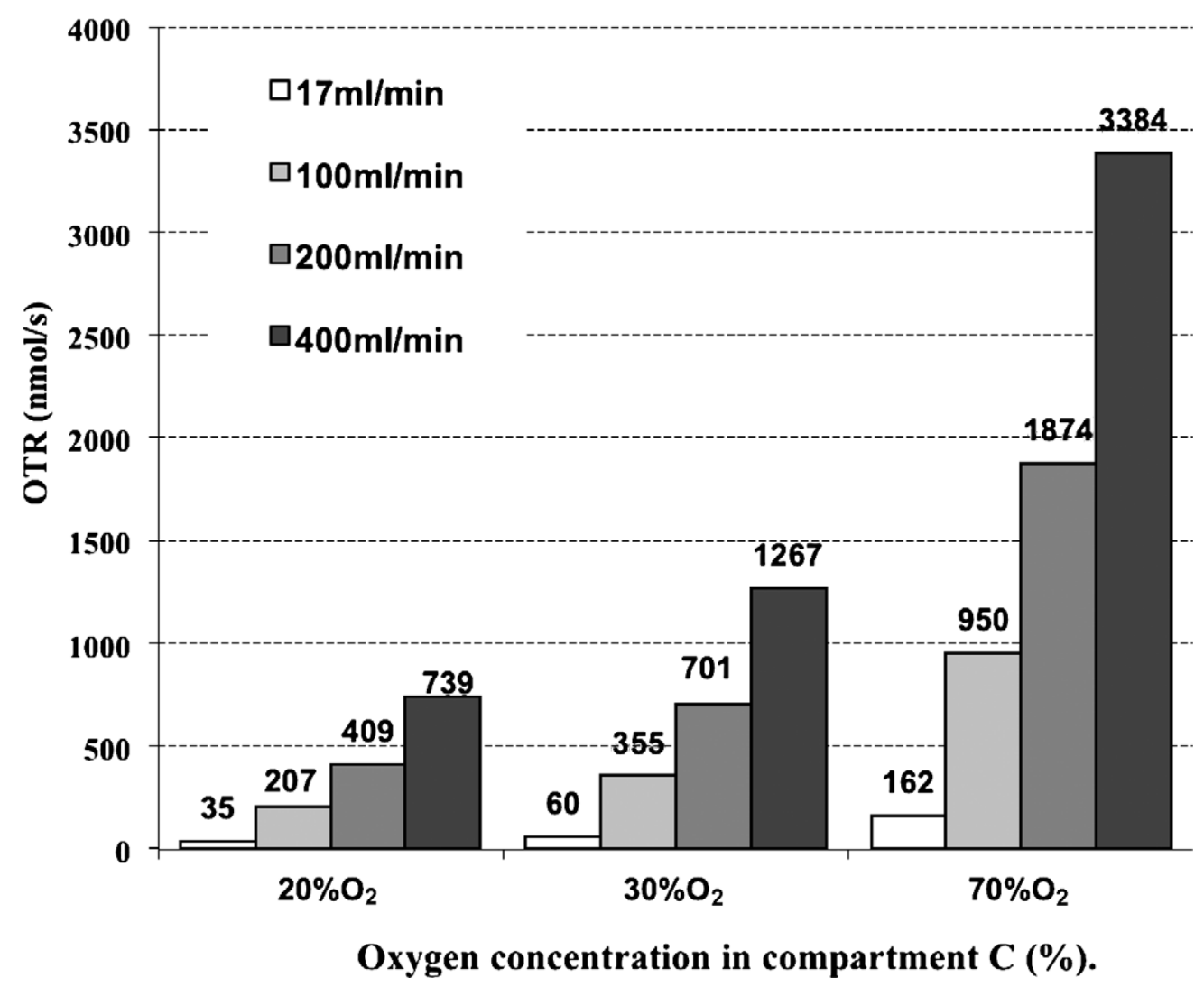

Fig. 9. Predicted OTRs in the lumen (compartment A) in the FIF bioreactor at different plasma flow rates and inlet oxygen concentration in compartment C. $\left(K=3 \mathrm{mmHg}[21], V_{\max }=10 \mathrm{nmol} / \mathrm{cm}^{3} \mathrm{~s}.\right)$

compartment B to compartment A. However, the difference was not that high, since the distance between the inner radius outer membrane and the outer radius of the inner membrane is relatively small $(0.48 \mu \mathrm{m})$. In addition, the flow distribution in compartment $\mathrm{A}$ is much better than in compartment $\mathrm{B}$ because of the expected interference between the two membranes.

In this paper, the proposed mathematical model extended the Krogh cylinder model by including one more zone for oxygen transfer from a gas compartment. The model has many assumptions in common with the Hay et al. [9] model. However, the effect of the gas compartment on the OTR is new to science and beneficial development. The reaction kinetics of substrate chemistry is nearly always assumed to be zero-order, first-order, or of Michaelis-Menten type, depending on whether enzyme or cell reaction rates are modelled [18,22]. In this study, cellular oxygen uptake was based on Michaelis-Menten kinetics. Most of the published studies on mathematical models used experimental data from literature to fulfil the dimensional and dimensionless parameters for model computation [9,23]. In this study, accurate results from conducted experiments on FIF bioreactor were compared with the predicted OTR for the purpose of validation of the mathematical model efficiency. The results from the model showed $85 \%$ matching with the experimental measurements for compartment A hydraulic pressure drop and the OTR to compartments A and B (Fig. 7).

The model created by Hay et al. [9] showed that the best match to experimental data across all values of inlet oxygen concentrations was found when $V_{\max }$ equals to $10 \mathrm{nmol} \mathrm{s}^{-1} \mathrm{~cm}^{-3}$. This value has been 
used in the current work. Figure 9 shows that the OTR increases as the oxygen concentration increases. These are expected results and supported by Patzer II [16].

The purpose of this study is to validate the mathematical model and evaluate the efficiency of the three compartments BAL devices in OTR. Changing some input parameters for the numerical implementation, e.g. $\mathrm{O}_{2}$ solubility in plasma, will help in studying the behaviour of the bioreactor in the presence of plasma. Other input parameters in further work may be added to describe the delivery/removal of, nutrients/waste products (e.g. lactate) to/from cell compartment. The effect of parameters, other than oxygen concentration in compartment $\mathrm{C}$ and perfusate flow rate, for example density of cells in compartment $\mathrm{B}$ on the OTR may also be studied and optimized by using the proposed model.

In the light of the results and discussion, the FIF bioreactor OTR performance could easily be affected by, (1) the nature of fluid used for the perfusion, (2) the membrane used to construct the bioreactors, (3) method of measurements and (4) the pressure applied. It is also expected that the performance of the newly designed bioreactor will be affected if the water is replaced by blood.

\section{Conclusion}

Novel FIF bioreactor for hepatocytes is developed. This bioreactor has a separate integral oxygenation in the outermost compartment by the creation of a third space, namely compartment $\mathrm{C}$. This integral oxygenation compartment should easily oxygenate the cells in compartment $\mathrm{B}$ to levels higher than $2 \mathrm{mmHg}$, ensuring that the cells are viable. The functionality of the newly developed FIF bioreactor has been verified in vitro. In vitro testing results were used to validate a newly developed mathematical model for FIF bioreactor and can be used for all tricentric hollow fibre bioreactors. Good matching was found between experimental and predicted results for compartments A and B hydraulic pressure drop and the OTR in compartment B.

\section{References}

[1] G.V. Mazariegos, D.J. Kramer and R.C. Lopez, Safety observations in the phase I clinical evaluation of the Excorp medical BLSS after the first four patients, ASAIO 47 (2001), 471-475.

[2] J.C. Gerlach, P. Lemmens, M. Schon, J. Janke, R. Rossaint, B. Busse, G. Puhl and P. Neuhaus, Experimental evaluation of a hybrid liver support system, Transplantation Proceedings 29 (1997), 852.

[3] F.D. Watanabe, W.S. Arnaout, P. Ting, A. Navarro, T. Khalili, Y. Kamohara, E. Kahaku, J. Rozga and A.A. Demetriou, Artificial liver, Transplantation Proceeding 31(2) (1999), 371-373.

[4] S.P. Wolfe, E. Hsu, L.M. Reid and J.M. Macdonald, A novel multi-coaxial hollow fibre bioreactor for adherent cell types. Part 1: Hydrodynamic studies, Biotechnology and Bioengineering 77(1) (2002), 83-90.

[5] A.J. Ellis, R.D. Hughes, J.A. Wendon et al., Pilot-controlled trial of the extracorporeal liver assist device in acute liver failure, Hepatology 24 (1996) 1446-1451.

[6] J.M. Millis, D.C. Cronin, R.C. Johnson, M.D. Conjeevaram, C. Conlin, S. Trevino and P. Maguire, Initial experience with the modified extracorporeal Liver Assist Device ELADTM for patients with fulminant hepatic failure: system modifications and clinical impact, Transplantation 74(12) (2002), 1735-1745.

[7] N.L. Sussman and J.R. Lake, Treatment of hepatic failure: Current concepts and progress towards liver dialysis, Scandinavian Journal of Kidney Diseases 27(5) (1996), 605-621.

[8] A. Demetriou, R. Brown, R. Busuttil, J. Fair, B. McGuire, P. Rosenthal et al., Prospective, randomized, multicenter, controlled trial of a bioartificial liver in treating acute liver failure, Ann. Surg. 239 (2004), 660-670.

[9] P.D. Hay, A.R. Veitch and J.D.S. Gaylor, Oxygen transport in a convection-enhanced hollow fibre bioartificial liver, Artificial Organs 25(2) (2001), 119-130.

[10] H.M. Yan, A. Ramachandran, M. Bajt, J. Lemasters and H. Jaeschke, The oxygen tension modulates acetaminopheninduced mitochondrial oxidant stress and cell injury in cultured hepatocytes, Toxicological Sciences 117(2) (2010), $515-523$. 
[11] S.L. Nyberg, R.A. Schatford, M.V. Peshwa, J.G. White, F.B. Cerra and W.S. Hu, Evaluation of a hepatocyte-entrapment hollow fibre bioreactor: A potential bioartficial live, Biotechnology and Bioengineering 41 (1993), 194-203.

[12] A. Hilal-Alnaqbi and J.D.S. Gaylor, Fibre-in-Fibre Bioartificial Liver device: Initial in vitro testing, International Journal of Biomedical Engineering and Technology 6(4) (2011), 323-336.

[13] M.D. Smith, A.D. Smirthwaite, D.E. Cairns, R.B. Cousins and J.D.S. Gaylor, Techniques for measurement of oxygen consumption rates of hepatocytes during attachment and post-attachment, International Journal of Artificial Organs 19 (1996), 36-44.

[14] G.A. Ledezma, A. Folch, S.N. Bhatia, U.J. Balis, M.L. Yarmush and M. Toner, Numerical model of fluid flow and oxygen transport in a radial-flow microchannel containing hepatocytes, Journal of Biochemical Engineering 121 (1999), 58-64.

[15] P.D. Hay, A.R. Veitch, M.D. Smith, R.B. Cousins and J.D.S. Gaylor, Oxygen transfer in a diffusion-limited hollow-fibre bioartificial liver, Artificial Organs Volume 24(4) (2000), 278-288.

[16] J.F. Patzer, Oxygen consumption in a hollow fibre bioartificial liver-revisited, Artificial Organs 28(1) (2004), 83-98.

[17] C. Heath, G. Belfort, B. Hammer, S. Mirer and J. Pimbley, Magnetic resonance imaging and modeling of flow in hollowfiber bioreactors, AICHE J. 36 (1990), 547-558.

[18] D. Das, Multiscale simulation of nutrient transport in hollow fibre membrane. Bioreactor for growing bone tissues: subcellular scale and beyond, Chem. Eng. Sci. 62 (2007), 3627-3639.

[19] J.M. Pei, $\mathrm{CO}_{2}$ and $\mathrm{O}_{2}$ exchange in cross flow and shell and tube artificial lungs, $\mathrm{PhD}$ Thesis, University of Strathclyde, 1991.

[20] J.M. Piret and C.L.C. Cooney, Mammalian cell and protein distributions in ultrafiltration hollow fibre bioreactors, Biotechnology and Bioengineering 36 (1990), 902-910.

[21] U.J. Balis, K. Behnia, B. Dwarakanath, S.N. Bhatia, S.J. Sullivan, M.L. Yarmush and M. Toner, Oxygen consumption characteristics of porcine hepatocytes, Metabolic Engineering 1 (1999), 49-62.

[22] R. Shipley, A. Davidson, K. Chan, J. Chaudhuri, S. Waters and M. Ellis, A strategy to determine operating parameters in tissue engineering hollow fiber bioreactors, Biotechnol. Bioeng. 108 (2011), 1450-1461.

[23] R.J. Shipley and S. Waters, Fluid and mass transport modelling to drive the design of cell-packed hollow fibre bioreactors for tissue engineering applications, Mathematical Medicine and Biology 29(4) (2012), 329-359. 